\title{
Design, Analysis and Installation of Offshore Instrumented Moored Data Buoy System
}

\author{
Kaliyaperumal, P., Venkatesan, R., Senthilkumar, P., Kalaivanan, C. K., Gnanadhas, T., and Vedachalam, N. \\ Ocean Observation Systems, Earth Science Systems Organization-National Institute of Ocean Technology, Chennai, 600100 India
}

\begin{abstract}
This paper discusses the analysis done on the meteorological ocean buoy mooring used for monitoring the Indian seas. Based on the extreme environmental parameters experienced by the buoys, mooring loads are analyzed using offshore dynamic analysis software. The results obtained are validated with the tension recorder installed in one of the moorings, and the results are found to comply with an accuracy of better than $1 \%$. The successful on demand performance of the mooring during major cyclones in the Bay of Bengal and the vital meteorological and oceanographic information provided by the buoy during these disastrous cyclonic events validates the mooring design, and proves the data availability for societal needs. The time critical data assimilated in the cyclone prediction models have given confidence to improve the country's weather prediction and climate modelling capabilities.
\end{abstract}

Key words: Mooring, data buoy, tsunami, cyclone.

\section{Introduction}

Oceans play a vital role in maintaining the Earth's climate, and its variability is due to the fluid motions, high heat capacity, and its ecosystems. The level of understanding the ocean environment and analysing in an appropriate spatio-temporal scale including its variability and to precisely model the weather and climate is a challenge [1]. Space-based observations of sea level through altimetry, surface wind stress through scattering studies and other passive sensing, sub surface temperature measurements through infrared and microwave techniques and precipitation through the Tropical Rainfall Measurement Mission using passive and active radar systems, are largely confined to surface variables measurements only [2, 3]. In situ observations provide an essential complement for validating the remotely acquired data and to obtain the subsurface variability. Knowledge of the ocean is essential for many stakeholders dealing with climatology, fisheries, ports and harbors, coastal zone management, navy and coast guard, public health and

Corresponding author: R.Venkatesan, Ph.D., research fields: marine pollution and management, ocean observation, ocean policy andmaterials for marine application. Email: venkat@niot.res.in. environment agencies, tourism, weather forecast, offshore mining and oil industry and climate research.

The buoy systems used for ocean monitoring is a floating structure designed to measure the ocean meteorological, surface and subsurface parameters. These buoy systems are categorized into moored and free drifting types, which in turn classified into surface and subsurface types. The buoy mooring is a structure that extends from the surface to the ocean bottom used for mounting meteorological and oceanographic instruments. Of late, MSB (Moored Surface Buoys) with precise data collection and real time transmission has revolutionized the observation system capabilities and their societal importance.

The top portion of the mooring is exposed to demanding environments and therefore its design should take into consideration the extreme effects of surface waves, ocean currents and other factors that vary with time, location, regional climate and weather patterns. Extensive research has to be done in this domain to understand the dynamics, load patterns, material needs and configuration. The study of the dynamics of anchored steel, polypropylene and nylon mooring lines disturbed by simple sinusoidal waves to 
predict the dynamic component of mooring line tension and it was reported that synthetic fiber ropes develop much lower dynamic tensions [4, 5]. The S-shaped inverse catenary mooring with sub-surface floats referred to as slack mooring is used for most of the deep sea instrumented mooring applications $[1,6]$. The importance on the need for efficient computational tools with capabilities to model all significant elements and physical processes related to the mooring system and to provide realistic predictions of loads, motions and displacements was discussed [6]. Extensive research is initiated for gaining further insight into the mechanism of the dynamic behaviour of mooring lines to quantify the effects of important parameters with special attention to the maximum tension developed [7].

Depending on the weight of the instruments attached to the mooring and based on the amplitude and frequency of the waves, large dynamic tensions are experienced specifically in the top portion of the mooring line. The cyclic loads with frequencies of about ten million times could be experienced in one-year operational period [8]. An analysis on single point inverse catenary mooring systems with and without subsurface floats showed that the most important design parameter in terms of the maximum tension is the length of the mooring. The other important parameter in terms of the bending fatigue damage is the length of the buoyant section and the distribution of the floats, which resulted in the design and development of instrumented moorings with the combination wire rope and synthetic ropes [9, 10]. Studies on the dynamics of mooring lines were conducted to provide a broad data base applicable to model validation and to quantify the horizontal and vertical components of the dynamic tension generated by the vertical and sinusoidal motions of the upper end of the mooring line which helps the designers to determine the bending stiffness and scope of the mooring line [11]. A comparison of the mooring line tension with two types of mooring systems and with the tension recorder measurements were also reported [12]. The finite element analysis software CABLE [13, 14] and OrcaFlex [15] were used for carrying out the static and dynamic analysis of oceanographic cable structures and to solve the surface and subsurface single-point mooring problems with user specified forces such as waves, currents, wind and ship speed. In this paper, an attempt has been made to compare the actual field recorded load measurements with the predicted mooring loads, using numerical analysis with CABLE and OrcaFlex software.

\section{Materials and Methods}

\subsection{Indian Moored Buoy System and Its Importance}

Considering the importance of ocean observations in terms of understanding our ocean environment and utilizing them for operational oceanography, the Ministry of Earth Sciences, Government of India, has installed a moored buoy network currently comprising of 24 MSBs to acquire different oceanographic parameters from the Indian Seas. The prime objective of the moored buoy network is to provide reliable, accurate and cost-effective atmospheric and oceanic observations for supporting weather forecasts and data exchange with international agreements on climate monitoring under the GOOS (Global Ocean Observation System) project. The data acquired are widely used for research, validation and operational applications in India and abroad. The OOS (Ocean Observation Systems) program of the ESSO National Institute of Ocean Technology is involved in the design, deployment and maintenance of meteorological and tsunami buoy networks in the Indian seas. The locations of MSBs are shown in Fig. 1. These buoy systems are deployed at particular locations, and are equipped with sensor suites to measure meteorological and oceanographic parameters. The state-of-the-art OMNI (Ocean Moored buoy network in the Northern Indian Ocean) buoy collects up to 106 parameters and transmits to the MCC (Mission Control Centre) in real time [1] at NIOT Chennai. 


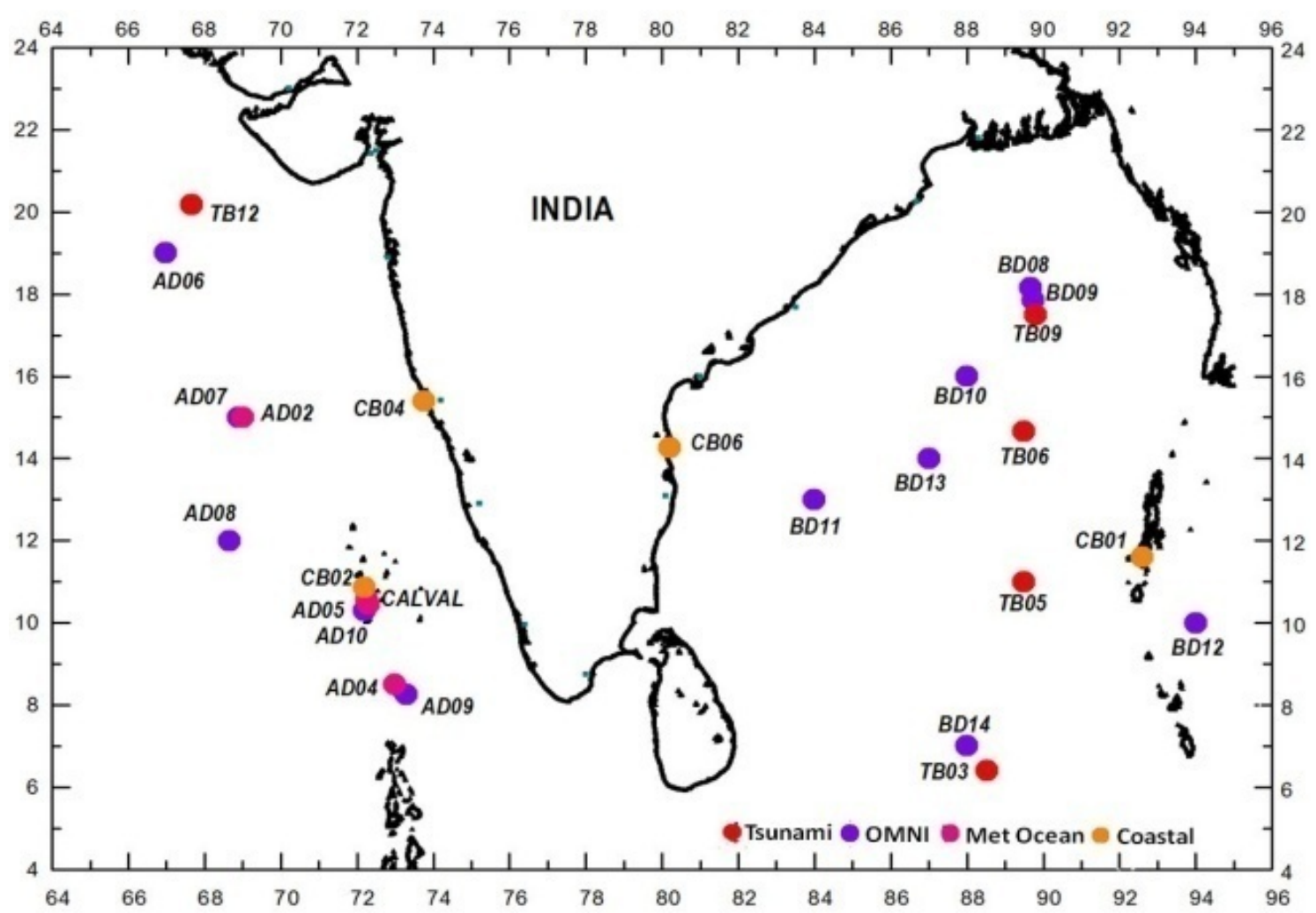

Fig. 1 Indian moored buoy network.

The acquired meteorological data are used by operational meteorological agencies such as the IMD (Indian Meteorological Department) for assimilating in their numerical weather models for precise weather forecasts. During the cyclone period, the wind and air-pressure data over the sea are crucial to initialize the models for forecasting the intensity and to track a cyclone. Similarly, the sub surface ocean temperature and salinity are being assimilated in the MOM-GODAS (Modular Ocean Model-Global Ocean Data Assimilation System) which is used for coupled ocean-atmosphere seasonal monsoon forecasts. The buoy is also used to monitor the sea level changes during a tsunami. The time series data provided by the buoys are imperative to understand the thermodynamics and resulting fluid dynamics of the ocean, and the air-sea interaction over the north Indian Ocean to assess the different temporal variations (diurnal, weekly, seasonal, semi-annual, annual, etc.) and to increase the degree of confidence in estimating the intensity and location of tropical cyclones [16].

\subsection{System Configuration}

The OOS group of NIOT, maintains three types of buoy systems, namely, the met ocean buoy system for measuring the surface parameter such as wind, humidity, air pressure, air temperature, wave, and surface current; OMNI buoy systems for measuring the meteorological parameters, such as the wind, humidity, air pressure and temperature, wave, radiation and rainfall, and subsurface parameters, such as current speeds up to $100 \mathrm{~m}$ depth, conductivity, temperature, salinity and pressure up to $500 \mathrm{~m}$ depth [2]; and Tsunami buoy systems, a co-located BPR(Bottom Pressure Recorder) with the surface buoy that measure the water column change sand communicate with the MSB acoustically, which are used to predict and to issue tsunami related warnings [17]. Depending on the type of application, a standard suite of sensors is integrated with the data acquisition system, which is capable of handling sensor outputs, average the data sets, and transmit the data through different telemetry 
channels. The entire system is programmed to collect data at pre-defined time intervals, store it, and transmit it from the MSB to the MCC. The surface buoy provides a platform to mount the sensors and their accessories, including the energy storage batteries and telemetry systems [1]. A discus shaped hull made of fiber reinforced plastic filled with polyurethane foam, offers a net buoyancy of about 2,000 kgf. The shape of the buoy hull enables it to perfectly follow the wave, which is of paramount importance for wave measurements [18].

Mooring is a compliant section between the surface buoy and the seabed located anchor, which protects the buoys from the action of the surface created forces. Moorings typically have three basic components: an anchor, mooring line with instrumentation and flotation devices that keep the mooring line and instrumentation in place. Shackles and links are used to connect the mooring components, and to secure the instruments in the mooring line. The choice of the hardware, mooring line and flotation for a particular application, as well as the size and design of the anchor, depends on the type of mooring and the environment in which it is deployed.

\subsection{Challenges in the Design of the Instrumented Buoy Mooring System}

The moorings are designed in such a way that the rope is not in contact either with the buoy hull or with the sea bed. For instrumented buoy mooring, the mooring should not influence the free motion of the buoy. As surface mooring is subjected to a hostile marine environment, it needs a form of built-in "compliance" (ability to stretch), to compensate for large vertical excursions, that the buoy may experience, during the course of tidal action and with passing waves and swell. The compliance should also compensate for the buoy displacements in lateral directions on the sea surface due to the drag forces induced by ocean wave and currents. In deepwater applications, compliance is provided through the use of synthetic ropes, nylon. The synthetic line acts like a rubber band that stretches if necessary, to maintain the connection between the surface-following buoy and the anchor at the bottom.

The basic idea of buoy mooring was evolved based on the concepts of traditional near-shore vessel mooring. The parameters to be considered in the design of instrumented buoy mooring systems are operational parameters including allowable amount of motion, and environmental parameters such as wind speed, current speed and wave parameters. In case of instrumented buoy mooring systems, the horizontal drift from the anchored position is critical, as the measurements need to be taken in a particular place and depth. The allowable buoy drift from its anchored position is termed as a watch circle.

The challenge in the design is to achieve an appropriate combination of structurally compliant and fish bite-resistant materials. The "scope" of the mooring (the ratio of the total un-stretched length of the mooring components to the water depth) is one of the critical design factors. A mooring with scope of less than one (taut mooring) relies on the stretch of the nylon for the anchor to reach the bottom. This mooring remains fairly vertical with a relatively small watch circle under considerable tension and the currents and waves impose additional loads [19].

Based on best of mooring practices published by pioneers such as NOAA NDBC (National Data Buoy Corporation) [20] and NIOT's operational experiences [21], the current operating mooring comprises of a single point "inverse catenary" link between the buoy and the anchor, which has a minimal effect on the wave loading because of its compliant section and higher scope. This design has specified lengths of wire rope in the upper part of the mooring and a nylon rope to form the required compliance section. A polypropylene rope is used in the remaining ocean depth up to the anchor along with the chain. The inverse catenary design offers a larger scope, typically 1.2 to 1.4 for high-current periods, and still performs well in lesser 
currents. In low currents, the buoyancy provided by the polypropylene rope and floats keeps the negatively buoyant nylon from entangling with the rest of the mooring. An instrumented mooring of inverse catenary design lowers the static mooring line tension. The dynamic tension contribution to the total tension, however, is unchanged, and care must still be taken in the design process to prevent the mooring from having a resonant response to forces in the range of surface wave periods. This type of mooring is less vulnerable to vandalism as there are no floating lines on the sea surface, which offers fish bite resistance in the upper ocean, and is easy for deployment, retrieval and servicing activities.

These moorings with inverse catenary configuration have three sections: the upper, the compliant and the lower sections. The upper section consists of a combination wire rope of $550 \mathrm{~m}$ length to protect the mooring from vandalism and fish bite. The compliance section has a nylon rope which gives an S-shape with the aid of sub-surface floats, and polypropylene rope provides sufficient stretch to the mooring line under extreme environmental conditions. The remaining length of the water depth contains the polypropylene rope and a $3 \mathrm{~m}$ chain, which is known as the lower section in the mooring. In order to avoid the rubbing of the chain with the sea bed, subsurface floats are added in the mooring line, which keep the chain in an upright position. The mooring scope in this case is about 1.2 to 1.4. Tsunami buoy moorings are also of inverse catenary design but with a lesser scope of about 1.04 to ensure reliable acoustic communication between the MSB and the bottom mounted pressure recorder [17]. In OMNI buoy moorings, induction cables are used instead of a combination rope, to mount the inductive sub surface sensors for real time and connector-less sub surface data transmission.

\subsection{Mooring Dynamic Modeling and in-Situ Measurements}

The total dynamic load on the oceanographic surface mooring is mainly attributed to the gravity forces and fluid drag on the attached mooring line components and the line tension [22]. Depending upon the buoyancy of the mooring hardware, gravity forces act based on the principles of Archimedes. The tension in the mooring line will be approximately equal to the immersed weight of all the mooring components, but in oceanic applications, due to currents, drag forces need to be considered in calculating the line tension as given below:

$$
P=W-B
$$

where, $P$-resultant force $(\mathrm{N} / \mathrm{m})$;

$W$-Weight of the body $(\mathrm{N} / \mathrm{m})$;

$B$-Buoyancy force $(\mathrm{N} / \mathrm{m})$.

In the direction normal to the flow, for a diameter (d) the hydrodynamic resistance due to drag is given by,

$$
R=1 / 2 \rho C_{d} A V^{2}
$$

Where, $R$-Drag force $(\mathrm{N})$;

$C d$-Coefficient of drag;

$A$-Frontal area $\left(\mathrm{m}^{\wedge} 2\right)$;

$P$-Fluid density $\left(\mathrm{kg} / \mathrm{m}^{\wedge} 3\right)$;

$V$-Velocity of fluid (m/s).

The drag coefficient varies depending on the nature of the fluid flow and type of exposed surface, and can be obtained by plotting the drag coefficient versus Reynolds number for flows, normal and tangential to the smooth and rough circular cylinders [23]. Under static equilibrium, the vector sum of these forces shall be zero. Applying these conditions for normal and tangential components of these forces, yields the resulting tension in the mooring lines.

In recent years, reliable and sophisticated computational tools are available for numerically analysing the mooring line-loads subjected to different environmental conditions. In the finite element method, the mooring line is divided into a number of straight segments, and the changes of tension that take place over a segment length are calculated. The numerical modelling of the mooring system and the equations of motion are solved, by using the time domain numerical simulation tool OrcaFlex and CABLE software. They 
are fully coupled 3D non-linear time domain finite element programs, capable of dealing with arbitrarily large deflections of the flexible line, in static and dynamic offshore conditions. Orcaflex provides fast and accurate analysis of catenary systems, such as flexible risers and umbilical cables under wave and current loads with externally imposed motions. It also has the capability to exactly model and analyse the buoy systems and their behaviour when subjected to different environmental conditions. In OrcaFlex, the line is divided into a series of segments, which are then modeled by straight mass less model segments, with a node at the end. The model of the line made with OrcaFlex is shown in Fig. 2 [15].

In order to study the deep sea inverse catenary mooring load in the in-situ condition and validate the numerical model results, a tension recorder is incorporated in a MSB (AD05) deployed in the Arabian Sea at $72^{\circ} \mathrm{E} / 10^{\circ} \mathrm{N}$ from December 2011 to September 2012. The tension recorder was fitted at the depth of $3 \mathrm{~m}$ approx. from the surface buoy, in line with the mooring, as shown in Fig. 3. The recorder (Model: Iokeys CTL-030 KN) is a robust and waterproof, battery operated unit, suitable for measurements of tension loads up to 3 tonnes $(30 \mathrm{kN})$. It consists of a compact electronic data recorder and a load cell tension sensor. The load cell generates an electrical signal that is measured and logged. The unit is capable of measuring tension every second for more than a year, with an internal battery, ensuring valuable information for long term research applications. The maximum, minimum and mean values of each measuring interval are stored in memory. Before deployment, the tension recorder was calibrated and programmed to measure the tension at 10 minutes intervals. The measured tension data were stored in the internal memory, totalling 41,754 data sets. This tension recorder has a resolution of $1.46 \mathrm{kgf}(14.4 \mathrm{~N})$ for the range of 2,997 $\mathrm{kgf}(29.4 \mathrm{kN})$ and an accuracy of $\pm 14.2 \mathrm{kgf}(140 \mathrm{~N})$.

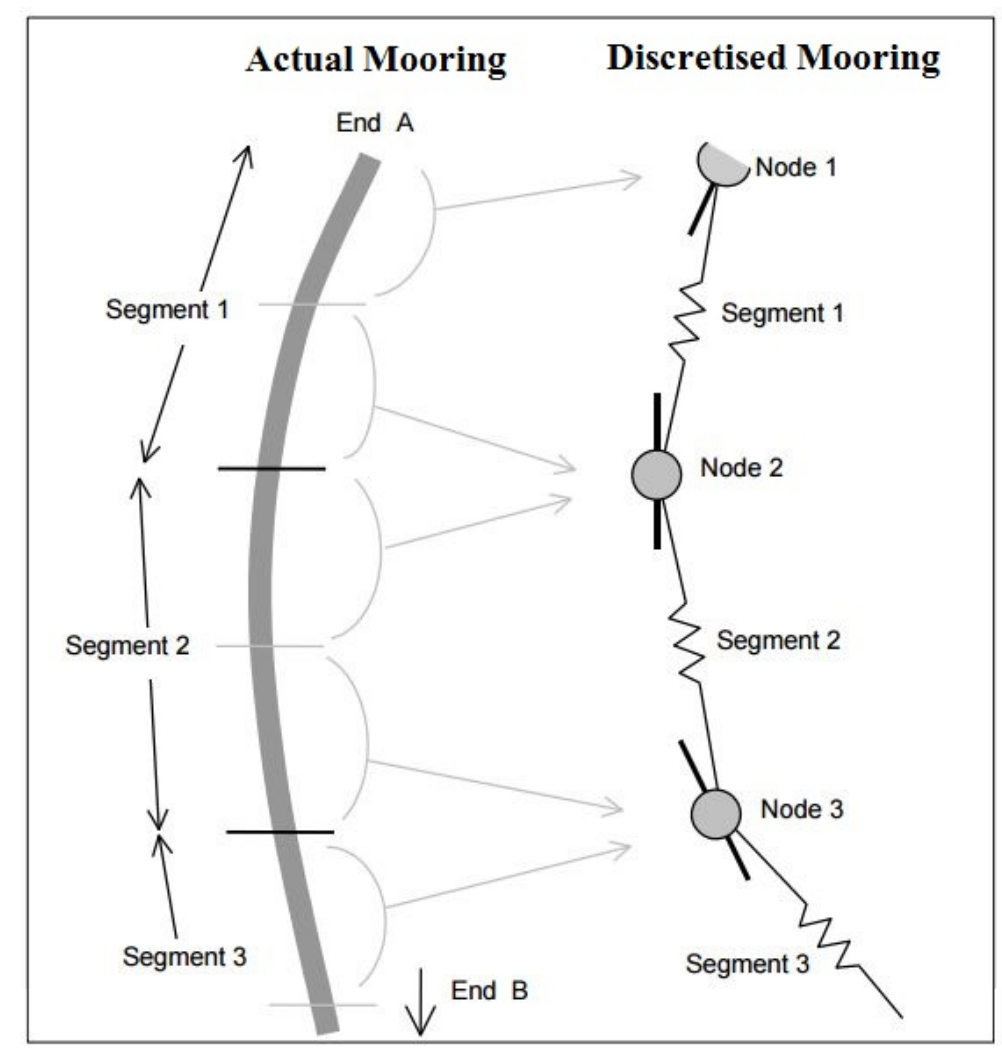

Fig. 2 OrcaFlex line model of mooring 


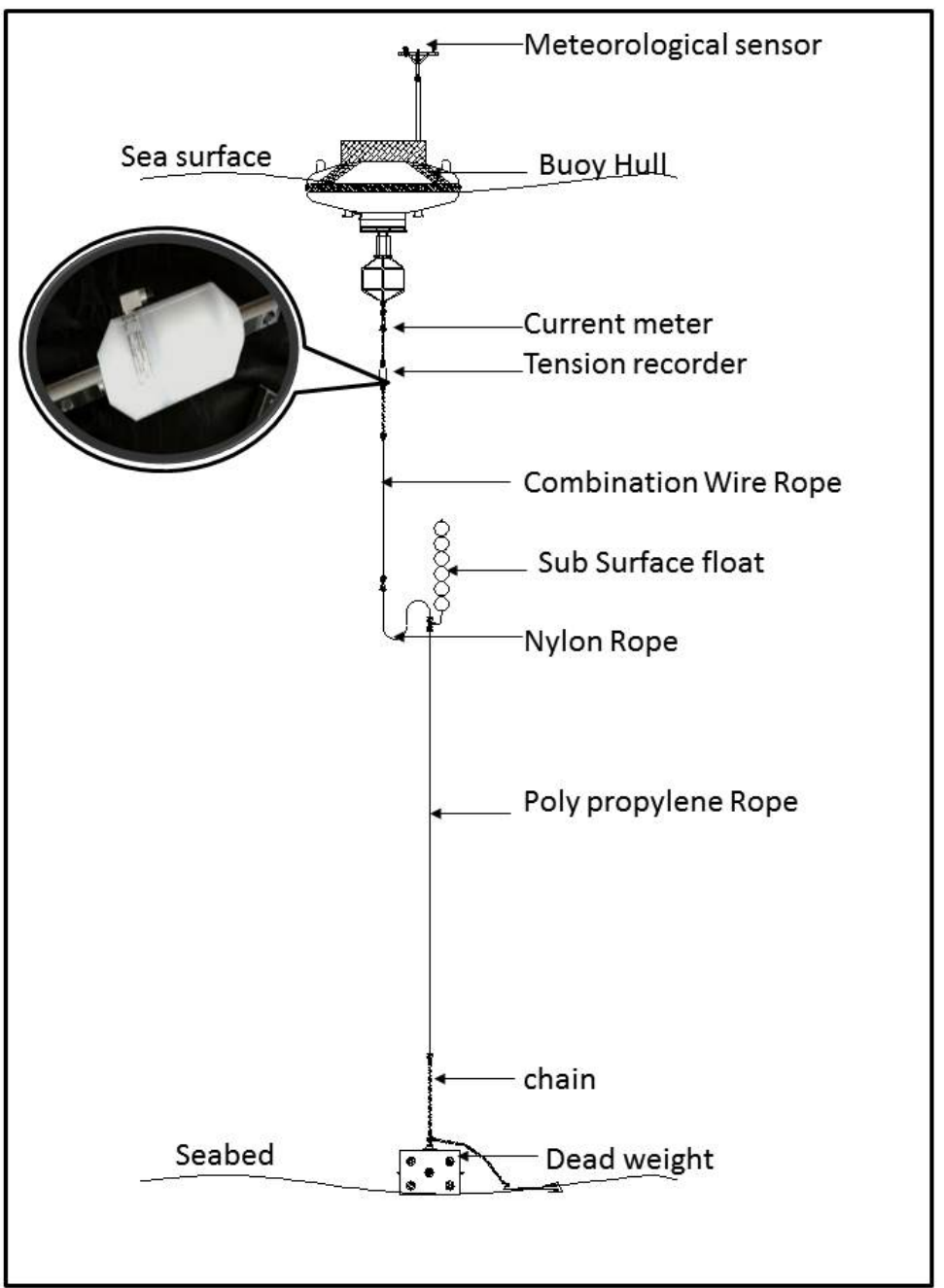

Fig. 3 Mooring line with tension recorder.

\subsection{Modeling of the Buoy and Mooring System}

The surface buoy is modelled as a spar buoy, so as to capture the interactions with the sea surface. Buoy geometry is defined in terms of a stack of cylinders, of appropriate diameters and length. The stack base and the centre of mass are positioned relative to a user-defined origin. Subsurface floats at the required depth are represented by a midline buoy attached to the line. The mooring line is made up of the required number of segments, and the respective material properties were assigned to each segment. The segment's length corresponding to the actual mooring component's length is given as an input. As the MSB is already equipped with sensors to measure ocean parameters, the actual environmental conditions measured at the location during the logged period were used for analysis. The environmental condition selected for modelling is the peak sea condition that occurred during the studied period.

From the graphs shown in Fig. 4, it is observed that the maximum values of current and wind were recorded on 12th June 2012, which is the extreme condition that existed during the period. The recorded values of the tension recorder are also plotted, and it shows the maximum, minimum and mean values over the entire deployment period.

By using these environmental parameters, the mooring analysis has been performed, the maximum tension in the mooring line is about 849 kgf, and that 
occurs just below the surface buoy. Fig. 5 below depicts the mooring line tension in the mooring line over the full simulation time and the results were compared with the actual measurements of the tension recorder.

\section{Results and Discussion}

The mooring line section just below the surface buoy, and lengths up to $500 \mathrm{~m}$ experience more tension compared with the remaining sections of the mooring. This is because the surface buoy transforms the full wave load to the mooring which is located just below it. Also, the drag force experienced at this section is high, as the surface current is comparatively high. There is a sudden decrease of the mooring load in the middle section as it is slack.
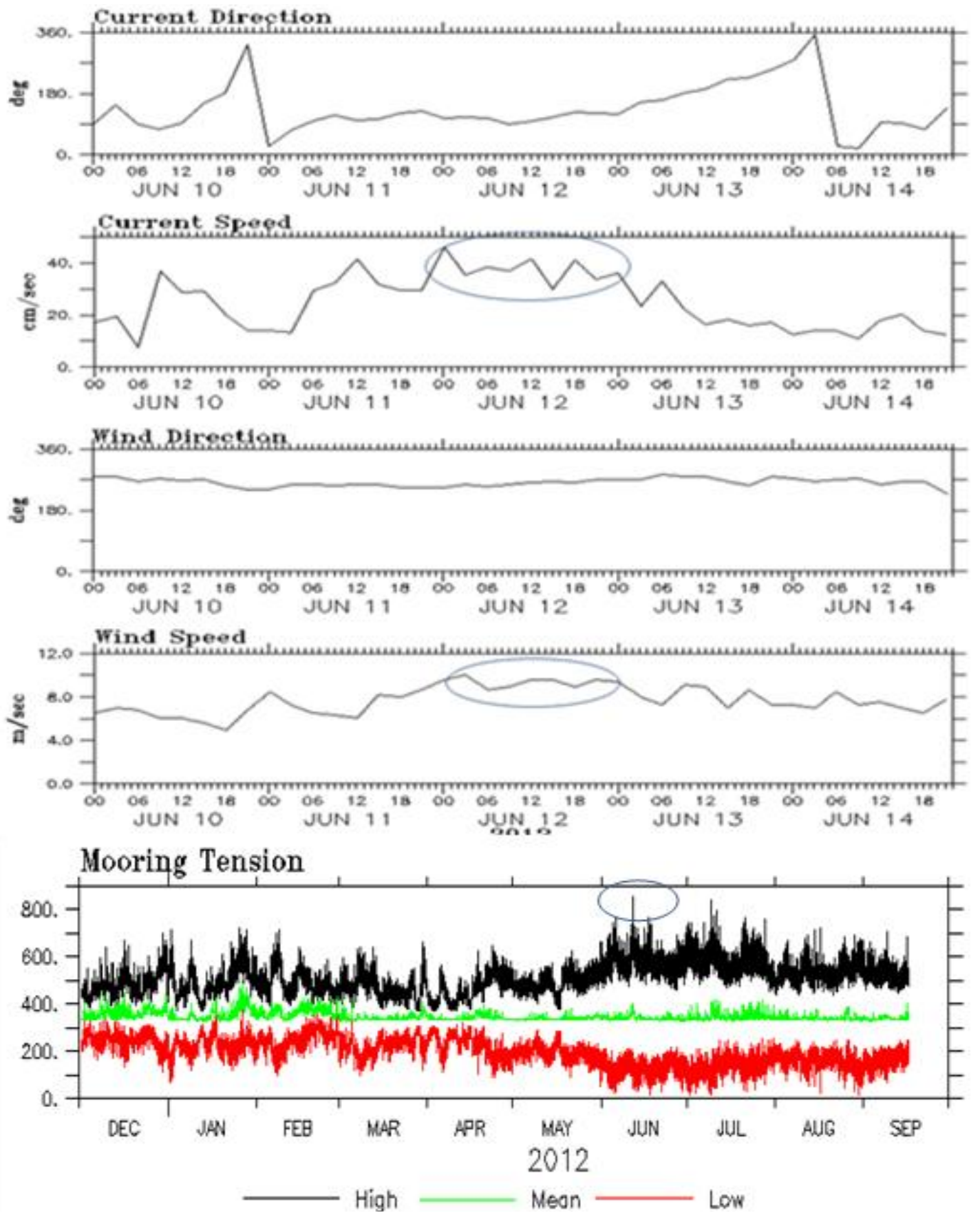

Fig. 4 Wind, surface current and mooring tension data plots from $\operatorname{AD05}\left(72^{\circ} \mathrm{E} / 10^{\circ} \mathrm{N}\right)$. 


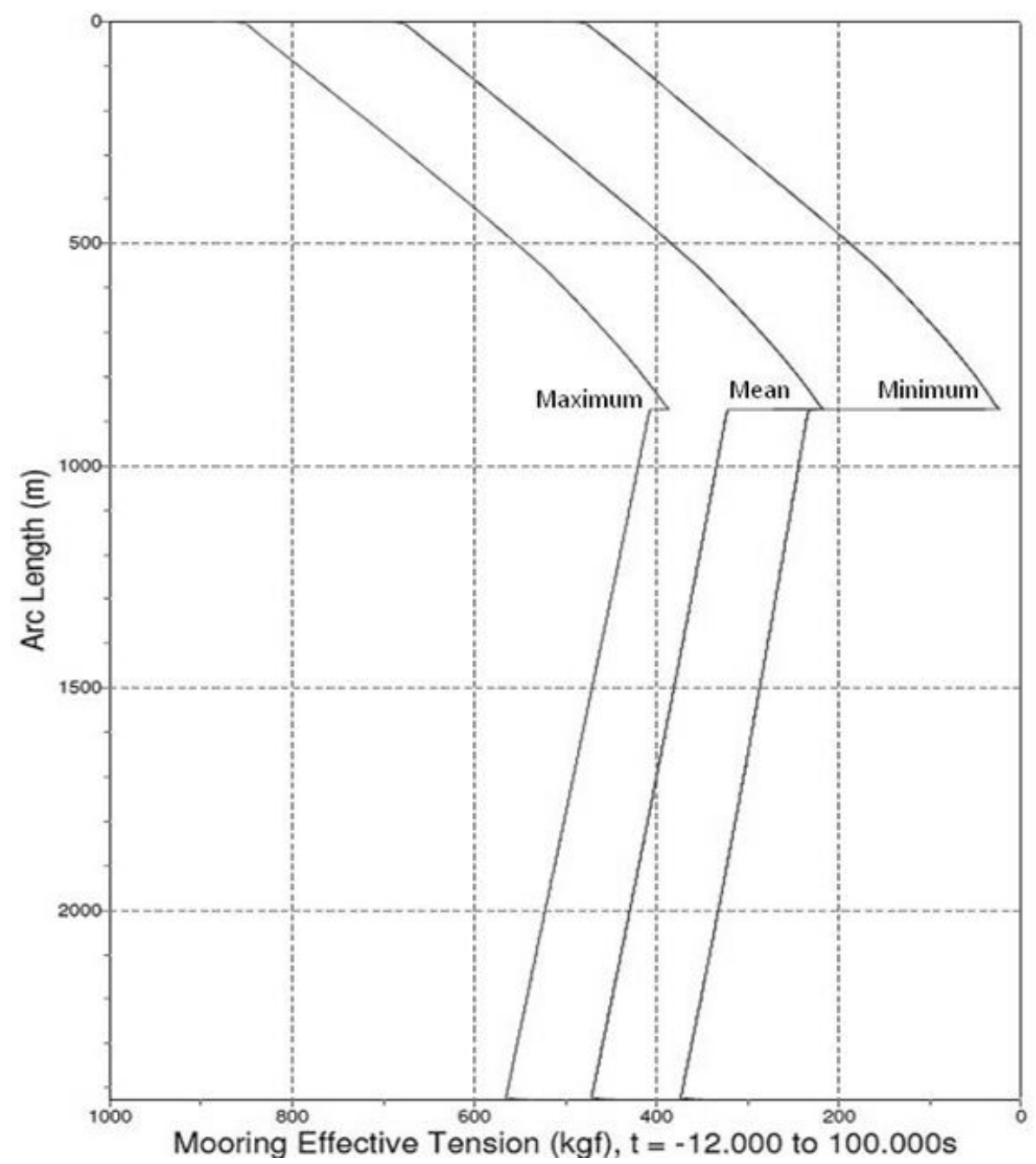

Fig. 5 Mooring line tension obtained from the numerical model.

A comparison has been made between the actual recorded values of the tension recorder and the predicted values. The maximum value recorded by the tension recorder during the whole deployment period is 854 kgf. This maximum value was recorded on 12th June 2012, the day on which peak environmental conditions existed during the deployment period.The predicted values are in close proximity to the actual value with an accuracy of better than $1 \%$. Thus, the maximum tension load predicted by OrcaFlex software is in good agreement with the tension recorder logged value.

\subsection{Mooring System Performance during the PHAILIN Cyclone}

The mooring buoy systems in the Bay of Bengal had tracked five cyclones since October 2011. The oceanic and atmospheric responses of three very severe cyclonic storms Mahasen, Phailin and Madi formed in the BoB during 2013 were captured by four OMNI buoys and one Metocean buoy. Fig 6 shows the maximum wind speed, wind gust and significant wave height recorded by the buoy network. The maximum value of wind speed recorded was $25.7 \mathrm{~m} / \mathrm{s}$ (10 minutes average at $1 \mathrm{~Hz}$ sampling frequency), and the wind gust was $32.81 \mathrm{~m} / \mathrm{s}$ (3 seconds average), during the passage of the MADI Cyclone [24] on 8th December 2013, and was recorded by BD11 $\left(13^{\circ} \mathrm{N} / 84^{\circ} \mathrm{E}\right)$. Also, the maximum significant wave height of $7.73 \mathrm{~m}$ was observed in the same buoy location on the same day.

A VSCS (very severe cyclonic storm) PHAILIN originated from a remnant cyclonic circulation in the 
Bay of Bengal

Arabian Sea

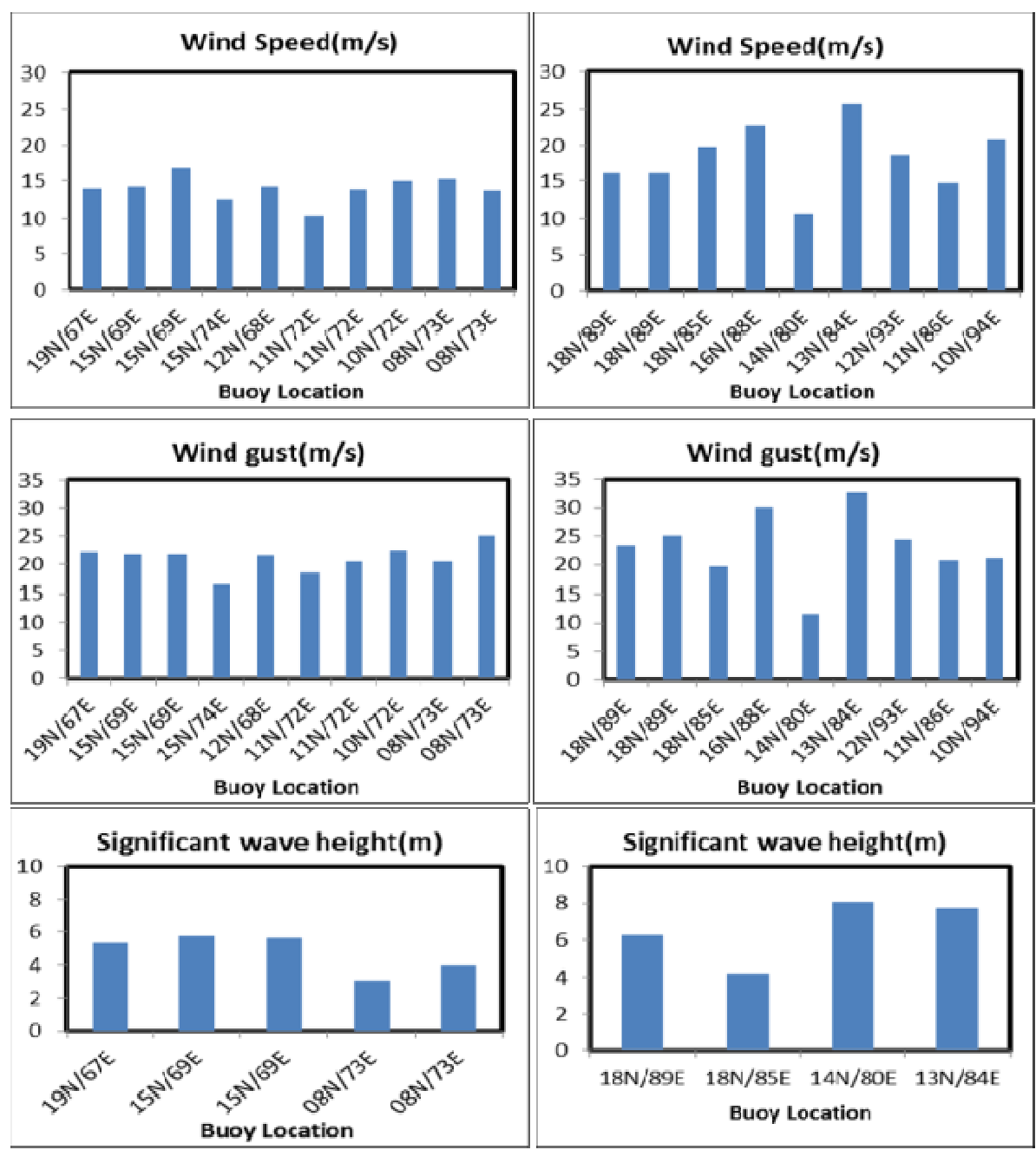

Fig. 6 Parameters measured by buoy network.

South China Sea [25]. It concentrated into a depression over the same region on 8th October 2013 near latitude $12^{\circ} \mathrm{N}$ and longitude $96^{\circ} \mathrm{E}$, moving west-northwestwards, intensified into a deep depression on 9th morning, and further, into a cyclonic storm, "PHAILIN" on the same evening. Moving northwestwards, it further intensified into a severe cyclonic storm in the morning and into a VSCS on the forenoon of 10th Oct, over the east central Bay of Bengal. The PHAILIN crossed Odisha and adjoining north Andhra Pradesh coast, near Gopalpur (Odisha) with a sustained maximum surface wind speed of 200-210 kmph [26], around 2,230 hrs IST of 12th
October 2013 and the same is shown in Fig. 7a [16].

During the passage of this cyclone, a MSB located at $16^{\circ} \mathrm{N} / 88^{\circ} \mathrm{E}$ in the eye of the cyclone experienced severe inertial oscillation, as shown in Fig. 7b, as evidenced by the surface buoy position, and the maximum recorded values of parameters were plotted in Fig. 7c.

As plotted in the watch circle diagram, during the passage of the Phailin cyclone, the buoy has moved outside the watch circle and remained till the end of the cyclone. It clearly indicates that the "compliance section" of the inverse catenary mooring has stretched enough, and kept the buoy intact with the anchor. 

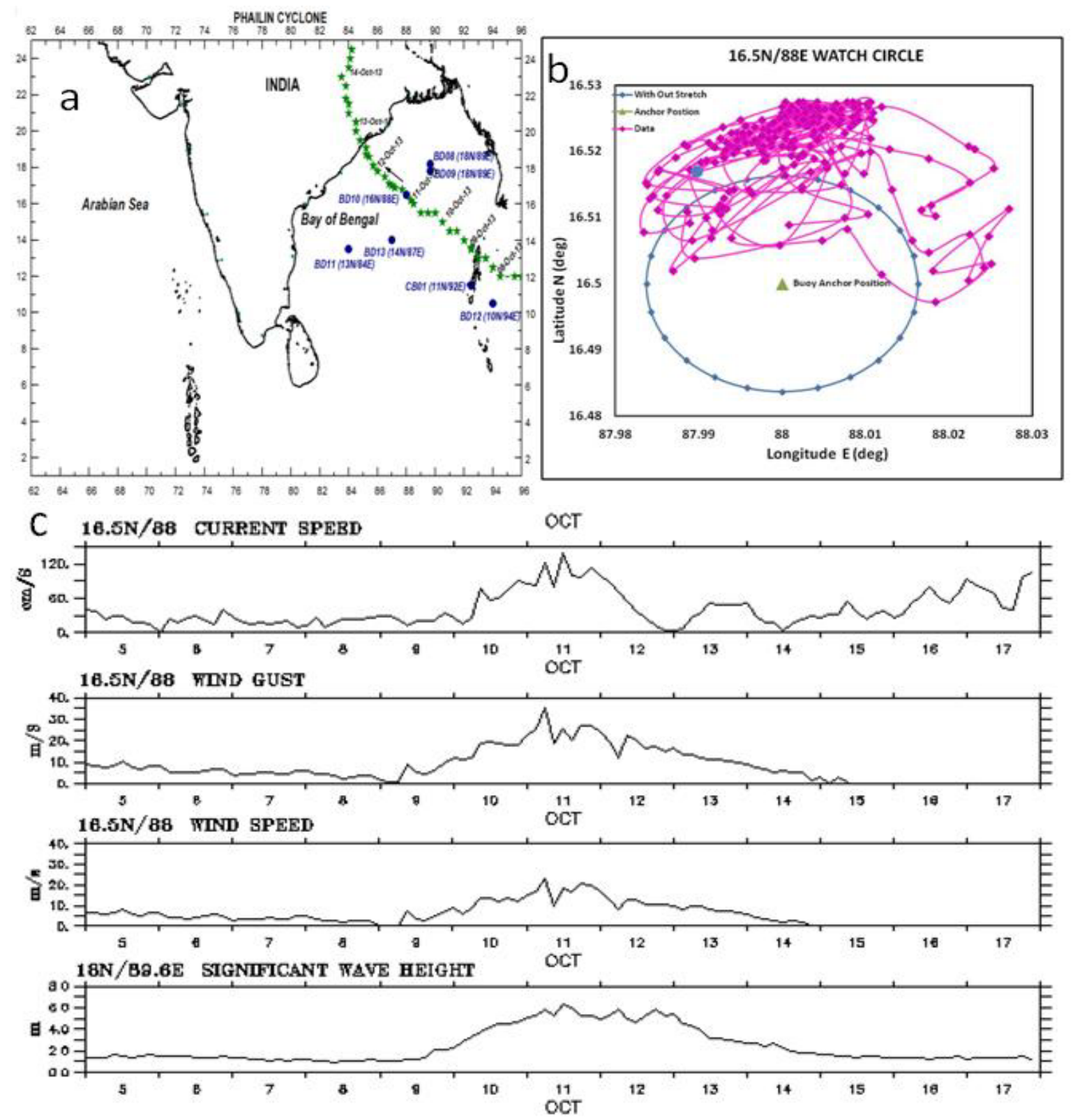

Fig. 7 (a) Phailin cyclone track; (b) Movement of buoy during the passage of cyclone [16]; (c) Significant observations during the Phailin cyclone.

Similar observations have been made during the passage of other cyclones, and the mooring remained intact in the respective locations.

\subsection{Inertial Oscillations and Mooring System} Performance during Other Cyclones

The inertial oscillation is a motion caused by the rotation of the earth, named Coriolis force. A sudden wind force will tend to push the surface water moving in the direction of the wind, but then, turn to the right hand side of the wind direction in the northern hemisphere because of the Coriolis effect. Once the motion is setup, the surface water will continue moving in a circle. This rotational motion is identified as inertial oscillation, where the word "inertial" refers to the effect of the inertial force induced by the rotation of the earth reference frame and the word "oscillation" is used, because the water particles will rotate in a circle. 
An object, free floating or moored at the location near to this, follows the pattern of this inertial oscillation.

The intensity of the current induced inertial oscillations has been observed independently, by lowered and moored current meters, by neutrally buoyant floats, and by electromagnetic current measurements. Inertial oscillations occur normally at the time of cyclones, and the buoy systems moored close to the travel path of these cyclones may experience the effect, and those which were reported on real time basis, and discussed. The OMNI buoy deployed in $\mathrm{BoB}$ at location $10^{\circ} \mathrm{N} / 88^{\circ} \mathrm{E}$ had captured the tropical cyclone JAL in November 2010 [27].

The OMNI buoy subsurface measurement system consists of nine numbers of water CT (conductivity and temperature) sensors mounted on the connector-less induction cable at pre determined depths, which measure and transmit the measured data to the buoy CPU inductively. In addition to that, an acoustic release is attached just above the dead weight to enable the retrieval of the induction mooring. The OMNI buoy deployed in the Northern BoB has recorded the time series observations of the surface meteorological and oceanographic parameters, during the passage of the tropical cyclone in November 2010, which attained cyclonic strength by 7th November 2010, moved west-north westwards, and crossed north Tamil Nadu.

The moored data buoy deployed in the Northern BoB provided significant information about the cyclone. The effect of the cyclone as well as the inertial oscillation on the buoy is clearly seen, in the time series plot (from 5th to 7th November 2010) of the buoy location shown in Fig. 8. Due to the passage of the cyclone, the buoy started moving in a circular path and remained in location.

\subsection{High Winds}

The buoy observations recorded the maximum significant wave height of $6.27 \mathrm{~m}$ as observed at $18^{\circ} \mathrm{N} / 89^{\circ} \mathrm{E}$ which was $140 \mathrm{~nm}$ away from the track of the cyclone, "Phailin". The buoy is deployed at a location where the depth is 2,150 m, and much offshore, thereby the wave height must have increased still higher as the cyclone approached the Gopalpur coast, India. The mooring withstood these high waves and upon retrieval of the MSB showed severe damage to the surface sensors. However, the buoy and mooring remained at this location. The photograph of the surface buoy taken from the Indian Research Vessel SAGAR KANYA is shown in Fig. 9. This is a clear indication of the success of the mooring design to withstand extreme weather conditions.

\subsection{Improved Mooring Designs}

The OMNI buoy system of NIOT is equipped with an ADCP (Acoustic Doppler Current profiler), which measures the current profiles up to $100 \mathrm{~m}$, which are used for oceanographic circulation models. The maximum

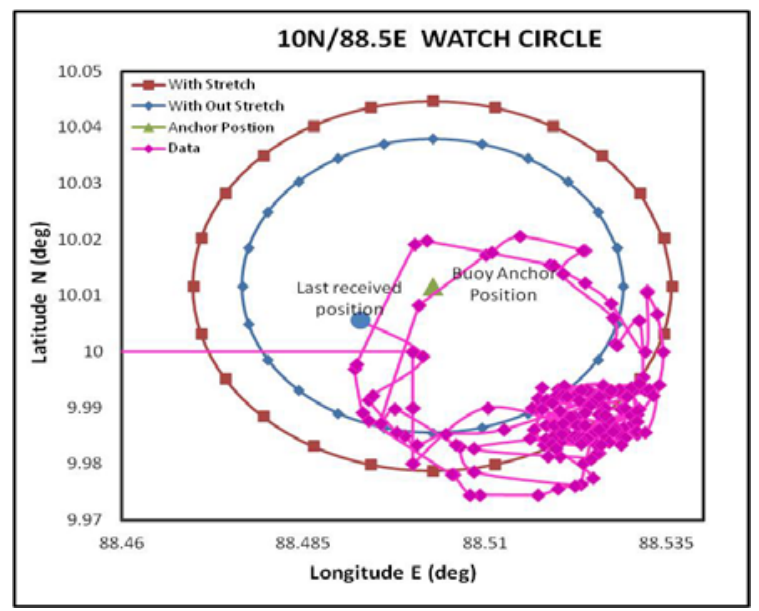

Fig. 8 Significant observations during the JAL cyclone.

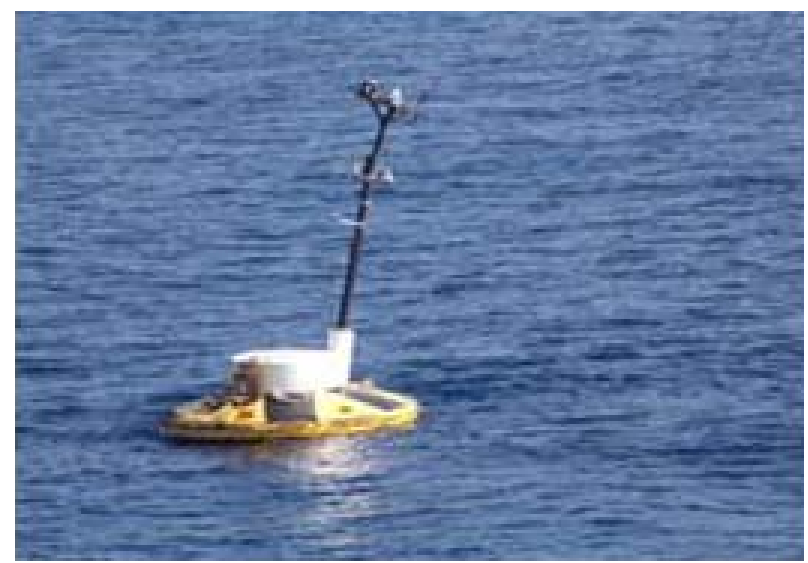

Fig. 9 Moored buoy after the PHAILIN cyclone. 
Table 1 Maximum recorded values of current speed.

\begin{tabular}{lllllll}
\hline \multirow{2}{*}{ Location ID } & \multicolumn{5}{c}{ Maximum Current Speed in different depths(cm/s) } \\
\cline { 2 - 6 } & $1.2 \mathrm{~m}$ & $10 \mathrm{~m}$ & $20 \mathrm{~m}$ & $30 \mathrm{~m}$ & $50 \mathrm{~m}$ & $100 \mathrm{~m}$ \\
\hline AD06(19N/67E) & 33.69 & 64.45 & 70.31 & 63.69 & 60.54 & 49.31 \\
AD07(15N/69E) & 46.36 & 65.42 & 74.70 & 67.38 & 76.66 & 98.14 \\
BD08(18N/89E) & 62.01 & 62.01 & 70.31 & 71.28 & 65.91 & 59.57 \\
AD09(08N/73E) & 141 & 129.35 & 102.05 & 104.49 & 76.17 & 72.26 \\
AD10(10N/72E) & 81.05 & 89.84 & 72.75 & 70.80 & 65.43 & 91.79 \\
BD08(18N/89E) & 99.84 & 90.82 & 88.37 & 83.49 & 77.14 & 73.24 \\
BD13(11N/86E) & 99.60 & 92.77 & 86.42 & 85.44 & 78.61 & 70.80 \\
BD12(10N/94E) & 93.75 & 84.96 & 78.12 & 78.12 & 76.17 & 83.98 \\
BD10(16N/88E) & 99.12 & 99.60 & 99.60 & 99.60 & 99.60 & 90.82 \\
BD09(18N/89E) & 99.12 & 97.65 & 98.14 & 97.65 & 93.26 & 93.26 \\
BD11(13N/84E) & 70.31 & 99.60 & 99.60 & 99.12 & 99.60 & 98.14 \\
BD14(18N/85E) & 98.63 & 96.19 & 99.60 & 95.70 & 98.14 & 86.42 \\
\hline
\end{tabular}

current values experienced from 1st November 2012 to 30th October 2013 are listed in Table. 1. The maximum surface current value of $141 \mathrm{~cm} / \mathrm{s}$ is recorded at the buoy station ID AD09 $\left(8^{\circ} \mathrm{N} / 73^{\circ} \mathrm{E}\right)$ is due to seasonal current system (northeast monsoon current) in the Northern Indian Ocean. In addition to the improved design practices, these values are expected to give guidelines for future designing of moorings in the respective locations.

\section{Summary and Conclusion}

This paper discusses the analysis done on mooring tension obtained using a numerical dynamic loadand compared with the actual value of tension recorded by the tension recorder fitted in the buoy. The model predicted tension load is in good agreement with the recorder logged value. The results are important for the validation of the model and its subsequent use in designing future deployments and testing the reliability of the model developed. The successful performance of the mooring during major Indian cyclones also helped in validating the mooring design. The acquired time critical meteorological and oceanographic data also helps to improve the weather prediction and climate modeling capabilities.

\section{Acknowledgements}

We thank Ministry of Earth Sciences, Govt. of India, for funding this project. We are grateful to the staff of OOS (Ocean Observation Systems) group, VMC (Vessel Management Cell) of NIOT and ship staff for their excellent help and support.

\section{References}

[1] Venkatesan, R., Arul Muthiah, M., Ramesh, K., Ramasundaram, S., Sundar, R., and Atmanand, M. A. 2013. "Satellite Communication Systems for Ocean Observational Platforms: Societal Importance and Challenges.” Journal of Ocean Technology (8): 47-73.

[2] Venkatesan, R., Shamji, V. R., Latha, G., Mathew, S., Rao, R. R., Arul Muthiah, A., and Atmanand, M. A.2013. "In Situ Ocean Subsurface Time Series Measurements from OMNI Buoy Network in the Bay of Bengal.”Current Science (104): 1166-77.

[3] Roy, C., and Kovordanyi, R. 2012. “Tropical Cyclone Track Forecasting Techniques-A Review.”Journal of Atmospheric Research (104-105): 40-69.

[4] Trenberth, K. E. 2004. "The Role of the Ocean in Climate." The State of the Ocean and the Ocean Observing System for Climate, Ed. D. M. Stanitski, Office of Climate Observations, NOAA, USA. Annual Rep 307: 1-6.

[5] Liu, H., Huang, W., Lian, Y., and Li, L. 2014. “An Experimental Investigation on Non-Linear Behaviors of Synthetic Fiber Ropes for Deepwater Moorings under Cyclic Loading.” Applied Ocean Research (45): 22-32.

[6] Evans, J. H., and Adamchak, J. C. 1969 Ocean Engineering Structures. Cambridge: M. I. T. Press.

[7] T. Mc Natt Catenary 1982. "Ocean Mooring Systems Approaches to Analysis and Testing”. OCEANS (82): 513-8.

[8] van den Boom. H.J.J. 1985. "Dynamic Behaviour of 
Mooring Lines.” In Proceedings of Behaviour of Offshore Structures: 359-68.

[9] Mark A. Grosenbaugh and Spyros A. Mavrakos 1995. "Design of Oceanographic Surface Moorings for Harsh-Weather Environments.” In proceedings of the 103rd Annual Meetings of the Society of Naval Architects and Marine Engineers: 395-423.

[10] Han S. M., and Mark Grosenbaugh 2006. "The Design of Single Point Cable Linked Moorings for Ocean Observations.” IEEE Journal of Ocean Engineering (31): 585-98.

[11] Mark A. Grosenbaugh 1996. "On The Dynamics of Oceanographic Surface Moorings.” Ocean Engineering (23): 7-25.

[12] John l. Pattison 1997. "Components of Force Generated by Harmonic Oscillations of Small Scale Mooring Lines in Water." David W. Taylor Naval Ship Research and Development Center, Report SPD (589): 3-5.

[13] Jason I. Gobat and Mark A. Grosenbaugh 2000. "WHOI Cable v2.0: Time Domain Numerical Simulation of Moored and Towed Oceanographic Systems.” Technical report of Woods Hole Oceanographic Institution. http://iop.apl.washington.edu/ jgobat/cable.pdf

[14] Prat, J., and Del Rio, J. 2013. "Simulations of a Moored Power Cable at OBSEA Platform”. In the Proceedings of OCEANS'13.

[15] OrcaFlex Manual, Version 9.8a. Orcina Ltd. Daltongate, Cumbria. 2014. http://www.orcina.com/SoftwareProducts/OrcaFlex

[16] Venkatesan, R., Simi Mathew, Vimala J, Latha G, Arul Muthiah, M, Ramasundaram, S., Sundar, R., Lavanya, R, and Atmanand, M. A. 2014. "Signature of Very Severe Cyclonic Storm Phailin in the Met-Ocean Parameters Observed by Moored Buoy Network in the Bay of Bengal.” Current Science (107): 589-95.

[17] Venkatesan, R., Vedachalam, N., Sundar, R., Arul Muthiah M., Prasad, P., and Atmanand M. A. 2015. "Assessment of the Reliability of the Indian Tsunami Buoy System.” Society of Underwater Technology (32): 255-70.
[18] Ricci, P., Rico, A., Ruiz-Minguela, P., Boscolo, F., and Villate, J. L. 2012. "Design, Modeling and Analysis of an Integrated Mooring System for Wave Energy Arrays.” In the Proceedings of 4th International Conference on Ocean Energy.

[19] Paul, W., Irish, J., Gobat, J., and Grosenbaugh, M. 1999. "Coastal Mooring Design: Taut Elastomeric and Chain Catenary Surface Buoy Moorings.” OCEANS '99 MTS/IEEE. Riding the Crest into the 21st Century (1):419-426.

[20] Gilhousen, D. B. 1998. "Improved Real Time Quality Control of NDBC Measurements.” Preprints of the 10th Symposium on Meteorological Observations and Instrumentation: 363-6. http://www.ndbc.noaa.gov/realtime.pdf.

[21] Venkatesan, R. 2011. "NIOT Document on Best of Practice Methods for Met-Ocean Buoys.”

http://www.iode.org/index.php?option=com_oe\&task=vi ewDocumentRecord\&docID=7573.

[22] Henry O. Berteaux 1976. "Oceanographic Buoy System.” In Buoy Engineering (2nd ed.), New York: John Wiley \& Sons: 197-265.

[23] Robet O. Reid and Basil W. Wilson 1962. "Boundary Flow Along a Circular Cylinder”, Technical Report of National Engineering Science Company (204).

[24] MADI IMD, 2013. "Very Severe Cyclonic Storm 'MADI' over Bay of Bengal.”

[25] IMD, 2013. "Very Severe Cyclonic Storm, PHAILIN over the Bay of Bengal: A Report.” New Delhi, India: Cyclone Warning Division, IMD.

http://www.imd.gov.in/section/nhac/dynamic/phailin.pdf

[26] Venkatesan, R., Arul Muthiah, M., Keshav Kumar, B., Sundar, R., Vedachalam, N., and Atmanand, M. A. 2015. "Evolution of Reliable and Cost-Effective Power Systems for Buoys Used in Monitoring Indian Seas.” Marine Technology Society Journal (49): 71-87.

[27] Venkatesan, R., Ramasundaram, S., Sundar, R., Vedachalam, N., Lavanya, R., and Atmanand, M. A. 2015. "Reliability Assessment of State-of-the-Art Real Time Data Reception and Analysis System for Indian Seas.” MTS (49):127-34. 